\title{
Calcium-Induced Calcium Release in EGTA-skinned Aortic Strips from Genetically Hypertensive and Normotensive Rats
}

\author{
Ernesto A. Aiello \\ and Angela O. Grassi de Gende, M.D.
}

\begin{abstract}
SUMMARY
The release of ${ }^{45} \mathrm{Ca}$ induced by $\mathrm{Ca}^{2+}$ was studied in genetically hypertensive (SHR) and normotensive (WKY) rats using EGTA-skinned aortic strips. Strips preloaded with ${ }^{45} \mathrm{Ca}$ (pCa 6.6) were desaturated at $5 \mathrm{mM}$ of EGTA. A slow component of the washout in aorta from SHRs exhibited higher $\mathrm{Ca}$ content and a lower rate of $\mathrm{Ca}$ leak than that in aorta from WKY rats. This slow component was stimulated during washing with $0.03,0.3,1$ or $10 \mu \mathrm{M}$ free $\mathrm{Ca}^{2+}$. The release of ${ }^{45} \mathrm{Ca}$ induced by $\mathrm{Ca}^{2+}$ proceeded at similar rates in preparations of the two strains. Compared to WKY aortic strips the stimulated efflux of ${ }^{45} \mathrm{Ca}$ was greater in SHR aortic strips due to the higher $\mathrm{Ca}$ content. About half of the release of ${ }^{45} \mathrm{Ca}$ induced by $1 \mu \mathrm{M}$ free $\mathrm{Ca}^{2+}$ during the first 6 minutes of stimulation was blocked by $0.6 \mathrm{mM}$ of ryanodine or $50 \mu \mathrm{M}$ of ruthenium red, thus identifying the sarcoplasmic reticulum as a source of Ca release. The results suggest that this intracellular storage of $\mathrm{Ca}$ in aorta from genetically hypertensive rats is relevant for the generation of high levels of cytosolic $\mathrm{Ca}^{2+}$. (Jpn Heart J 36: 247-257, 1995)
\end{abstract}

Key words: Genetically hypertensive rats EGTA-skinned aortic strips $\mathrm{Ca}^{2+}$-induced $\mathrm{Ca}^{2+}$ release Sarcoplasmic reticulum

$\mathrm{T}$ HE function of systems involved in the regulation of the cytosolic concentration of $\mathrm{Ca}^{2+}$ in vascular smooth muscle cells has been the subject of many studies which aimed to determine the cellular mechanism underlying the increase in vascular tone of genetically hypertensive rats. Concerning the $\mathrm{Ca}$ channels of the sarcolemma, a higher influx of $\mathrm{Ca}^{2+}$ through the receptor operated ones ${ }^{1,2)}$ and similar ${ }^{1,3)}$ or higher effluxes ${ }^{4)}$ through the voltage operated ones, have been described in vascular smooth muscle cells from SHRs compared to

From Anatomia y Fisiologia, Departamento de Ciencias Biológicas, Facultad de Ciencias Exactas, Centro de Investigaciones Cardiovasculares, Facultad de Ciencias Médicas, Universidad Nacional de La Plata, Argentina.

This work was supported by grant PID No. 306220088 from the CONICET.

Address for correspondence: Dr. Angela O. Grassi de Gende, Gátedra de Anatomia y Fisiologia, Departamento de Ciencias Biológicas, Facultad de Ciencias Exactas, Calles 47 y 115-1900 La Plata, Argentina. Received for publication May 17, 1994.

Accepted February 6, 1995. 
those from WKY rats. On the other hand, the extrusion of cytosolic $\mathrm{Ca}^{2+}$ carried out by the $\mathrm{Ca}^{2+}$-ATPase of sarcolemma has been proved to be depressed in genetically hypertensive rats. ${ }^{5,6)}$ Any of these abnormalities leading to high $\mathrm{Ca}^{2+}$ levels in the cytosol might directly increase the vascular tone in SHRs. Simultaneously, intracellular Ca stores, namely the sarcoplasmic reticulum, could load more $\mathrm{Ca}^{2+}$ and then be able to release larger amounts for activation of contraction. An increased $\mathrm{Ca}$ uptake has been reported in intact aortic smooth muscle cclls from SHRs ${ }^{7}$ but the contribution of the SR in determining the vascular tone of SHRs has been usually assessed with mechanical studies. Results comparing the contractile response of vessels from genetically hypertensive and normotensive rats to agonists that mobilize $\mathrm{Ca}^{2+}$ from intracellular stores, are controversial. Lower ${ }^{8,9,10)}$ and higher ${ }^{1,8,11)}$ contractions in vessels of SHRs compared to those in vessels of WKY rats have been reported.

This work was aimed at a more direct assessment of intracellular $\mathrm{Ca}^{2+}$ sources in vessels of genetically hypertensive and normotensive rats. Using EGTA-treated aortic strips, ${ }^{45} \mathrm{Ca}$ content, unstimulated ${ }^{45} \mathrm{Ca}$ efflux and $\mathrm{Ca}^{2+}$ stimulated ${ }^{45} \mathrm{Ca}$ efflux were determined in both strains. Preparations of SHRs are shown to release larger amounts of $\mathrm{Ca}$ upon stimulation with micromolar levels of free $\mathrm{Ca}^{2+}$ than those of WKY rats.

\section{Methods}

Adult male rats (16-24 weeks) of genetically hypertensive (SHR) and normotensive (WKY) strains, weighing 250-350 g, were used after 3-4 determinations of their systolic pressure in the tail artery by using the plethismographic method. Mean values of 26 rats in each group were $187 \pm 3 \mathrm{mmHg}$ for SHR and $133 \pm 2 \mathrm{mmHg}$ for WKY. Rats were anesthetized with Na pentobarbital $(80 \mathrm{mg} /$ $\mathrm{kg}$ body weight ${ }^{-1}$, i.p.) and the aorta removed, cleaned of connective tissue and washed in ice cold saline. Strips of 3-5 mg were blotted, weighed and attached to a stainless steel hook $(0.22 \mathrm{~mm}$ diameter). The chemical skinning of plasma membrane was performed by overnight exposure of strips to a solution at $4^{\circ} \mathrm{C}$ containing $5 \mathrm{mM}$ EGTA, $170 \mathrm{mM} \mathrm{K}$ propionate, $2.5 \mathrm{mM} \mathrm{MgCl}_{2}, 2.5 \mathrm{mM}$ $\mathrm{Na}_{2} \mathrm{ATP}$ and $10 \mathrm{mM}$ Hepes buffer, $\mathrm{pH}$ 7. Similar procedures have been used to skin strips of cardiac tissue. ${ }^{12)}$

Unstimulated efflux of $\mathbf{C a}^{2+}$ : Strips treated with EGTA were incubated for 30 minutes in $1 \mathrm{~m} l$ of an uptake solution containing (in $\mathrm{mM}$ ) $1.6{ }^{45} \mathrm{Ca}$-EGTA (radioisotope from New England Nuclear), $3.4 \mathrm{EGTA}, 170 \mathrm{~K}$ propionate, $2.5 \mathrm{MgCl}_{2}$, $5 \mathrm{Na}_{2} \mathrm{ATP}$ and 10 Hepes buffer, $\mathrm{pH}$ 7. The free $\mathrm{Ca}^{2+}$ concentration of $0.25 \mu \mathrm{M}$ was obtained by diluting CaEGTA buffer stocks prepared with known concentrations of $\mathrm{CaCO}_{3}$ and EGTA, and calculated with the computer program of 


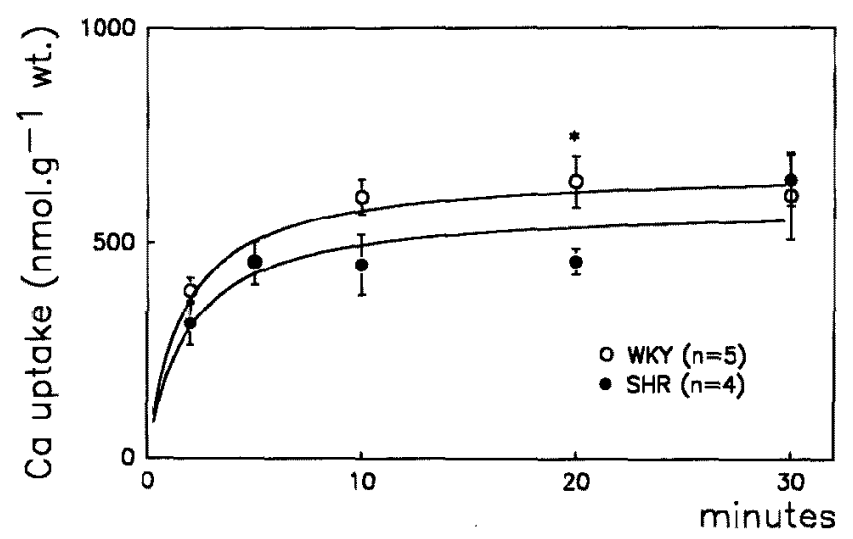

Figure 1. ${ }^{45} \mathrm{Ca}$ accumulation at different times of incubation in the uptake solution described in Methods. After the strips were loaded with ${ }^{45} \mathrm{Ca}$ they were washed for 30 minutes in solutions containing $50 \mu \mathrm{M}$ of ruthenium red and $10 \mathrm{mM} \mathrm{MgCl}$; under these conditions the extrareticular ${ }^{45} \mathrm{Ca}$ is eliminated and the loss of ${ }^{45} \mathrm{Ca}$ from the intrareticular compartment is prevented. * indicates $p<0.05$.

Fabiato. ${ }^{13)}$ Control experiments were performed in order to demonstrate that after 30 minutes of exposure to the above uptake solution the accumulation of ${ }^{45} \mathrm{Ca}$ was saturated in aortic strips from SHR and WKY rats (Figure 1). In the efflux experiments after the period of ${ }^{45} \mathrm{Ca}$ load, the strips were successively immersed in $2 \mathrm{~m} l$ of a desaturation solution at the time intervals indicated in the figures. Desaturation solution contained (in $\mathrm{mM}$ ) 1 or 5 EGTA, $170 \mathrm{~K}$ propionate, $1 \mathrm{MgCl}_{2}, 5 \mathrm{Na}_{2} \mathrm{ATP}$ and 10 Hepes buffer, $\mathrm{pH} 7$. At the end of the washing, the strips were digested by overnight exposure to $1 \mathrm{ml}$ of $1 \mathrm{~N} \mathrm{NaOH}$. Radioactivity in samples obtained during washing and in digested tissue was measured in a liquid scintillation counter (Beckman LS-3133P). Decay of ${ }^{45} \mathrm{Ca}$ content during the period of washing was adjusted by non linear regression to a double exponential decay function. From these curves, the values of both extrapolated $\mathrm{Ca}$ content at time zero and half time of washing ( $\mathrm{T}$ 1/2) of the fast and slow components identified were calculated.

${ }^{45} \mathrm{Ca}$ stimulated efflux of $\mathbf{C a}^{2+}$ : Skinned strips were loaded with ${ }^{45} \mathrm{Ca}$ as described above and then washed with the desaturation solution containing $5 \mathrm{mM}$ EGTA for 20 minutes followed by 12 minutes of washing with desaturation solutions that contained appropriate amounts of Ca-EGTA buffer, thus attaining a final concentration of EGTA of $5 \mathrm{mM}$, free $\mathrm{Ca}^{2+}$ concentrations of $0.03,0.3,1$ or $10 \mu \mathrm{M}$. Four samples at 3 min intervals were collected during the washing with each of these free $\mathrm{Ca}^{2+}$ concentrations followed by a return to the initial desaturation solution ( $5 \mathrm{mM}$ EGTA) for 6 minutes. With values of ${ }^{45} \mathrm{Ca}$ content in the digested tissue and in samples at each time interval, the efflux of ${ }^{45} \mathrm{Ca}$ and the fraction of ${ }^{45} \mathrm{Ca}$ lost per minute (rate coefficient) were calculated under stimu- 
lation with the four free $\mathrm{Ca}^{2+}$ concentrations assayed. In order to test the sensitivity of ${ }^{45} \mathrm{Ca}$ efflux induced by micromolar concentrations of free $\mathrm{Ca}^{2+}$ to agents that specifically block the $\mathrm{Ca}$ channels in sarcoplasmic reticulum, the stimulation was performed in the presence of $0.6 \mathrm{mM}$ of ryanodine or $50 \mu \mathrm{M}$ of ruthcnium red. ${ }^{14)}$ This concentration of ryanodine blocked the SR-Ca ${ }^{2+}$ relcasc channels in rat cardiac homogenates ${ }^{14)}$ and it is close to the one described to achieve maximal deactivation of the action of ryanodine $(1 \mathrm{mM})$ on skeletal and cardiac SR-Ca ${ }^{2+}$ release channels in SR vesicles. ${ }^{15)}$

Statistical analysis was performed using the Student's $t$ test for independent samples when comparing means of normotensive and hypertensive groups, and the one-way analysis of variance with the Peritz' $\mathbf{F}$ test for differences between stimulations of ${ }^{45} \mathrm{Ca}$ efflux in the absence and presence of $\mathrm{Ca}$ channels blockers. The level of statistical significance was set at $p<0.05$.

\section{Results}

EGTA-treated aortic strips preloaded with ${ }^{45} \mathrm{Ca}$ for 30 minutes were washed with desaturation solutions containing 1 or $5 \mathrm{mM}$ of EGTA. The work from Stout and Diecke ${ }^{16)}$ used segments of tail artery from WKY rats, skinned by treating them with $0.1 \mathrm{mg} / \mathrm{ml}$ of saponin and $5 \mathrm{mM}$ EGTA for 60 minutes at $20^{\circ} \mathrm{C}$. We used protocols of load and washout in our EGTA skinned aortic strips similar to those showing the sensitivity to caffeine and submicromolar free $\mathrm{Ca}$ of a slow compartment in the tail artery. ${ }^{16)}$ Figure 2 shows data of ${ }^{45} \mathrm{Ca}$ content in tissue during the period of washing. The washout of ${ }^{45} \mathrm{Ca}$ was initially fast, corresponding with a compartment that has been associated with extracellular and cytosolic spaces in the saponin-skinned vessels. ${ }^{16)}$ The half time of washing for this fast component did not differ between hypertensive and normotensive rats. Values were $0.80 \pm 0.10$ vs $0.84 \pm 0.15 \mathrm{~min}$ at $1 \mathrm{mM} \mathrm{EGTA}$ and $0.71 \pm 0.06$ vs 0.66 $\pm 0.04 \mathrm{~min}$ at $5 \mathrm{mM}$ EGTA for the WKY and SHR groups, respectively. The slow component in washout curves had values of extrapolated Ca content slightly higher, but without statistical significance, in SHR than in WKY rats at both EGTA concentrations (Table I). Since the half time of washing was shorter in the normotensive strain at $5 \mathrm{mM}$ of EGTA, a greater content of $\mathrm{Ca}$ in the hypertensive strain became significant after ten minutes of washing (Figure 2, B). Ca retained by this slow component could be considered as Ca sequestrated in SR of skinned smooth muscle cells without the participation of mitochondria, since at $0.25 \mu \mathrm{M} \mathrm{Ca}^{2+}$ in the uptake solution, an azide-sensitive fraction could not be detected in saponin-skinned vessels. ${ }^{17)}$ Four concentrations of free $\mathrm{Ca}^{2+}$ were assayed during the ${ }^{45} \mathrm{Ca}$ washout of strips preloaded with ${ }^{45} \mathrm{Ca}$ at the time when the slow component was being washed. Figure 3 shows the effects of 0.03 (A), 0.3 


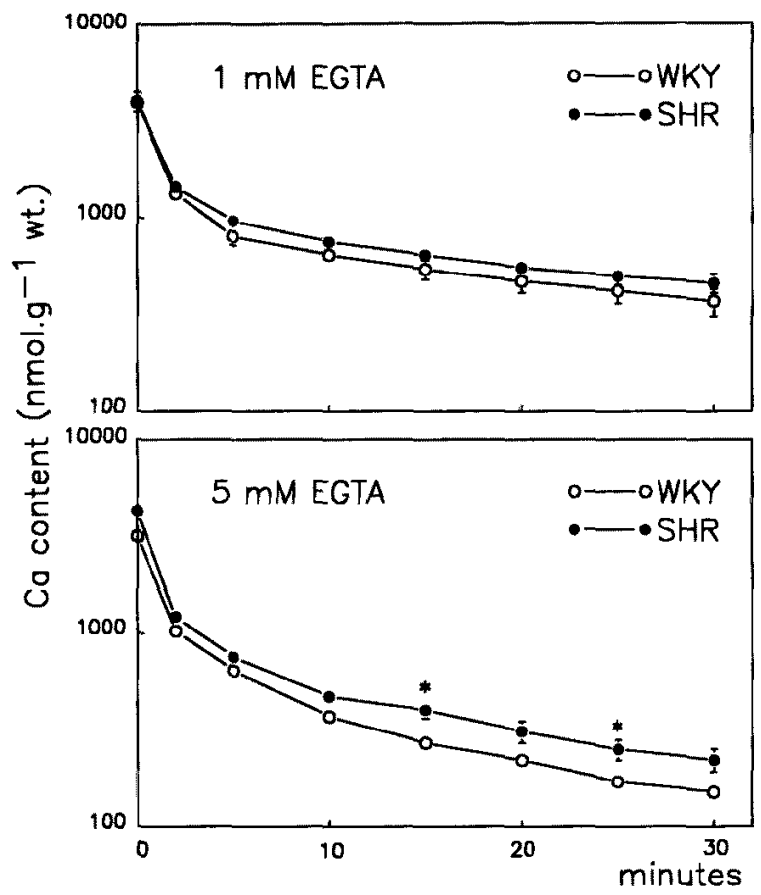

Figure 2. Ca content in tissue during desaturation of ${ }^{45} \mathrm{Ca}$ preloaded EGTA-treated aortic strips from SHR and WKY rats. Washing solutions contained 1 or $5 \mathrm{mM}$ EGTA. A significantly higher Ca content of the slow component in strips of SHR is evident with $5 \mathrm{mM}$ EGTA. Ca content was lowered by washing with $5 \mathrm{mM}$ EGTA, which suggests that this concentration was necessary to achieve a full buffering of ${ }^{45} \mathrm{Ca}$ efflux from this intracellular compartment in both strains. A similar value was found to control changes in cytosolic free $\mathrm{Ca}^{2+}$ of skinned caudal arteries. ${ }^{14)}$ Values are mean \pm SEM for the number of experiments indicated in Table $\mathrm{I}$.

Table I. Ca Content (nmol.g ${ }^{-1}$ wt) and Half Time of Wash $\left(\mathrm{T}^{1 / 2}\right.$, min) of the Slow Component Identified in Washouts of ${ }^{45} \mathrm{Ca}$ Loaded Strips from SHR and WKY Rats

\begin{tabular}{|c|c|c|c|c|}
\hline & \multicolumn{2}{|c|}{$1 \mathrm{mM}$ EGTA } & \multicolumn{2}{|c|}{5 mM EGTA } \\
\hline & Ca content & $T^{1 / 2}$ & Ca content & $T^{1 / 2}$ \\
\hline \multirow[t]{2}{*}{ WKY } & $870 \pm 90$ & $23 \pm 2$ & $790 \pm 90$ & $11 \pm 0.6$ \\
\hline & \multicolumn{2}{|c|}{$(n=4)$} & \multicolumn{2}{|c|}{$(n=5)$} \\
\hline \multirow[t]{2}{*}{ SHR } & $1010 \pm 40$ & $25 \pm 3$ & $840 \pm 70$ & $14 \pm 0.8^{*}$ \\
\hline & \multicolumn{2}{|c|}{$(n=4)$} & \multicolumn{2}{|c|}{$(n=5)$} \\
\hline
\end{tabular}

* indicates $p<0.05$ between values of WKY and SHR groups.

(B), 1 (C) and 10 (D) $\mu \mathrm{M}$ free $\mathrm{Ca}^{2+}$ on rate coefficient values of strips from both strains. No differences in the increases in rate coefficient induced by $0.03,0.3,1$ and $10 \mu \mathrm{M}$ free $\mathrm{Ca}^{2+}$ were detected between the normotensive and hypertensive groups (Figure 3 and Table II). The efflux of ${ }^{45} \mathrm{Ca}$ during stimulation with the different free $\mathrm{Ca}^{2+}$ concentrations was greater in strips from SHRs than in strips 


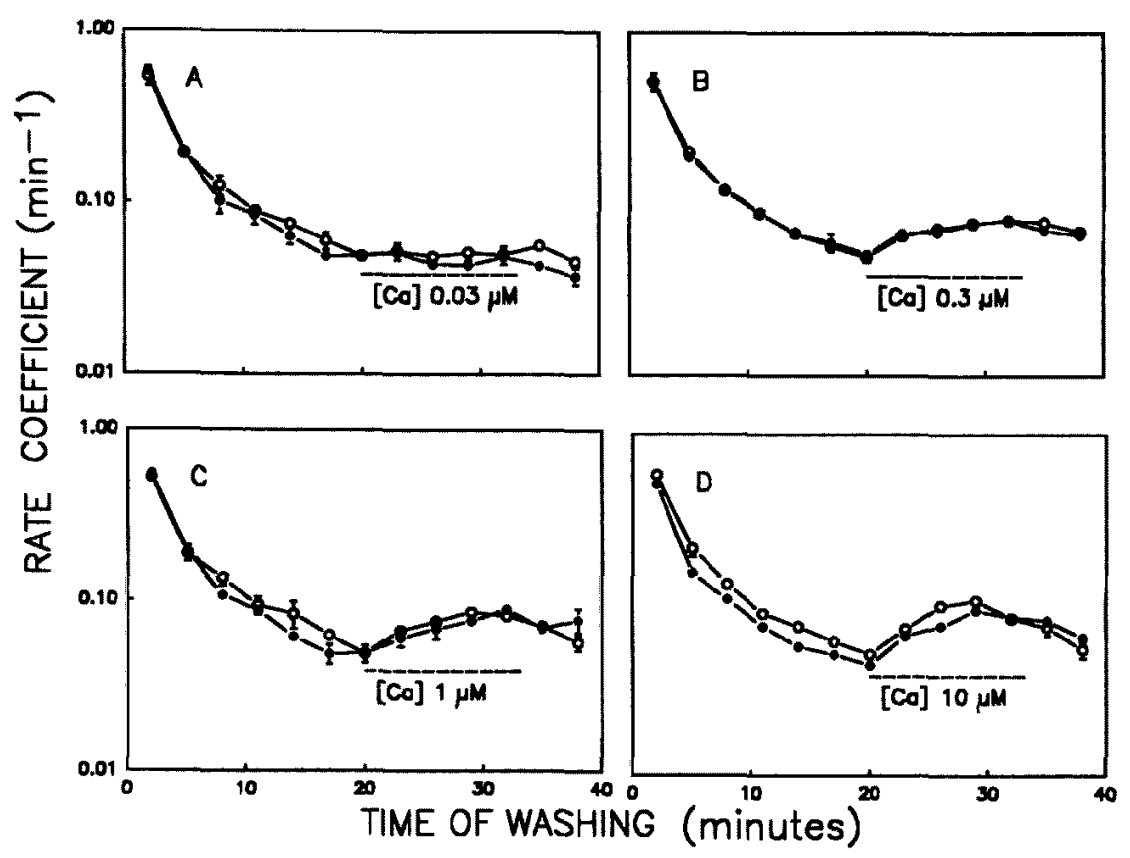

Figure 3. Effects of submicromolar and micromolar free $\mathrm{Ca}^{2+}$ concentrations on ${ }^{45} \mathrm{Ca}$ efflux from skinned aortic strips of WKY rats (O) and SHRs (O). Tissues were loaded at $0.25 \mu \mathrm{M}$ free ${ }^{45} \mathrm{Ca}^{2+}$ for 30 minutes and desaturated in $5 \mathrm{mM}$ EGTA until 20 minutes, followed by a period of 12 minutes with washing solutions containing 0.03 (A), 0.3 (B), 1 (C) or 10 (D) $\mu \mathrm{M}$ free $\mathrm{Ca}^{2+}$, and then a return to $5 \mathrm{mM}$ EGTA for 6 minutes. The horizontal bars indicate the time interval of stimulation. The increases in rate coefficient induced were $\mathrm{Ca}$ concentration dependent (Table II). Values of $\mathrm{Ca}$ content previous to the stimulation as well as of efflux of Ca corresponding with these figures are shown in Table III. Points are means \pm SEM of four expenments for each calcium concentration.

Table II. Maximal Increments in Rate Coefficient, Expressed as \% of the Value at the 20th Minute of Washing, during Stimulation with Different Free $\mathrm{Ca}^{2+}$ Concentrations

\begin{tabular}{lcccc}
\hline$\left[\mathrm{Ca}^{2+}\right] \mu \mathrm{M}$ & 0.03 & 0.3 & 1 & 10 \\
\hline WKY & $23 \pm 11$ & $69 \pm 6$ & $92 \pm 18$ & $117 \pm 5$ \\
SHR & $9 \pm 6$ & $71 \pm 11$ & $90 \pm 20$ & $112 \pm 14$ \\
\hline
\end{tabular}

from WKY rats, providing that the content of Ca was significantly higher in the hypertensive preparations (Table III). At $0.03 \mu \mathrm{M}$ free $\mathrm{Ca}^{2+}$, where statistically significant changes in rate coefficient were not detected, the efflux of ${ }^{45} \mathrm{Ca}$ was higher in SHR than in WKY. Thus, under both unstimulated and stimulated rate of $\mathrm{Ca}$ release, the aortic strips from genetically hypertensive rats lose more $\mathrm{Ca}$ than those of the normotensive control group. 
Table III. Ca Content before Stimulation (nmol.g ${ }^{-1} \mathrm{wt}$ ) and $\mathrm{Ca}$ Efflux for the Whole

Period of Stimulation (nmol.g-1 wt.12 $\mathrm{min}^{-1}$ ) with Different free $\mathrm{Ca}^{2+}$ Concentrations

\begin{tabular}{lllcc}
\hline & \multicolumn{2}{c}{ Ca content } & \multicolumn{2}{c}{ Ca efflux } \\
\hline$\left[\mathrm{Ca}^{2+}\right] \mu \mathrm{M}$ & WKY & SHR & WKY & SHR \\
0.03 & $159 \pm 18$ & $227 \pm 23^{*}$ & $72 \pm 6$ & $96 \pm 6^{*}$ \\
0.3 & $183 \pm 5$ & $201 \pm 9$ & $108 \pm 5$ & $119 \pm 6$ \\
1 & $158 \pm 2$ & $210 \pm 18^{*}$ & $96 \pm 3$ & $122 \pm 8^{*}$ \\
10 & $151 \pm 18$ & $230 \pm 8^{*}$ & $100 \pm 12$ & $142 \pm 3^{*}$ \\
\hline
\end{tabular}

* indicates $p<0.05$ between values of WKY and SHR groups.

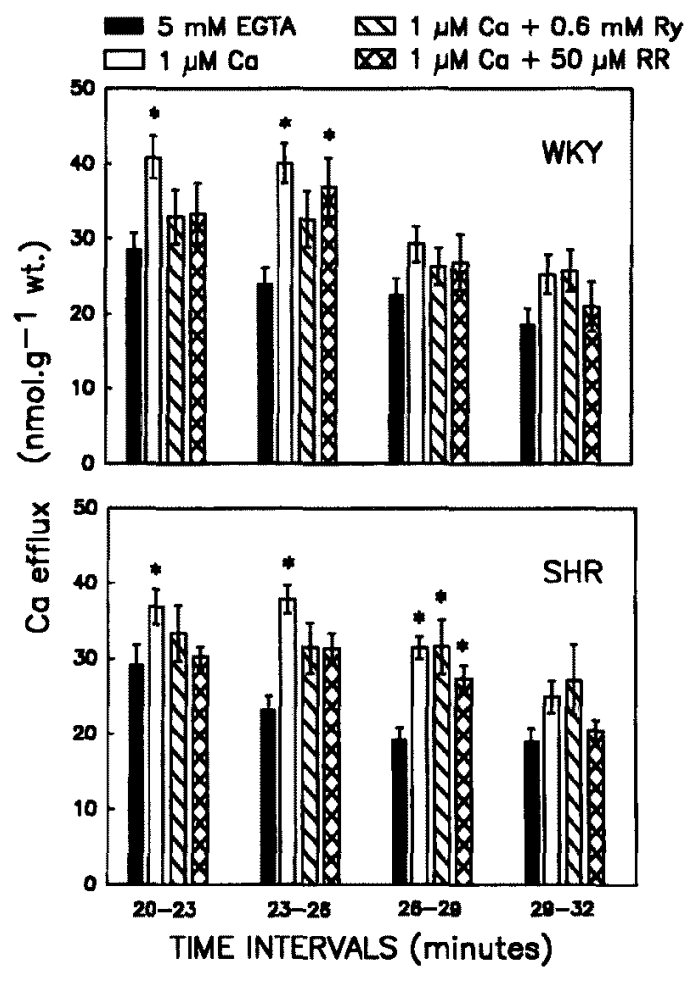

Figure 4. Efflux of ${ }^{45} \mathrm{Ca}$ at the time intervals where a free $\mathrm{Ca}^{2+}$ concentration of 1 $\mu \mathrm{M}$ was applied. The pre and post-stimulation effluxes are not shown. Effluxes induced in the absence and presence of $0.6 \mathrm{mM}$ ryanodine $(\mathrm{Ry})$ or $50 \mu \mathrm{M}$ ruthenium red (RR) by $1 \mu \mathrm{M}$ free $\mathrm{Ca}^{2+}$ are compared among them and with the efflux without stimulation. The SR channel blockers suppressed about $40-50 \%$ of the Ca efflux induced by $\mathrm{Ca}^{2+}$ during the first 6 minutes of stimulation. Bars represent mean values with indication of the SEM for the same number of experiments in WKY and SHR under the different washing conditions: $5 \mathrm{mM}$ EGTA $=14,1 \mu \mathrm{M}$ free $\mathrm{Ca}^{2+}=8,1 \mu \mathrm{M}$ free $\mathrm{Ca}^{2+}$ plus $0.6 \mathrm{mM}$ ryanodine $=6$, and $1 \mu \mathrm{M}$ free $\mathrm{Ca}^{2+}$ plus $50 \mu \mathrm{M}$ ruthenium red $=$ $5 .{ }^{*}$ indicates $p<0.05$ stated by the Peritz' $\mathrm{F}$ test between unstimulated (black bars) and stimulated efflux of $\mathrm{Ca}$. 
Figure 4 shows the effects of ryanodine and ruthenium red on the release of ${ }^{45} \mathrm{Ca}$ induced by $1 \mu \mathrm{M}$ frec $\mathrm{Ca}^{2+}$. Compared with the unstimulated efflux (black bars), during the first 3 minutes the efflux was stimulated by $1 \mu \mathrm{M}$ free $\mathrm{Ca}^{2+}$ only in the absence of SR-Ga channels blockers (open bars). Computing the net releases induced by $1 \mu \mathrm{M}$ frec $\mathrm{Ca}^{2+}$ during the first 6 minutes of stimulation they were reduced by $54 \%$ for WKY and $43 \%$ for SHR in the presence of ryanodine, and by $37 \%$ for WKY and $58 \%$ for SHR in the presence of ruthenium red. Thus, about half of the Ca efflux induced by $1 \mu \mathrm{M}$ free $\mathrm{Ca}^{2+}$ during this period was through the SR calcium channels.

\section{Discussion}

$\mathrm{Ca}^{2+}$-induced $\mathrm{Ca}^{2+}$ release is shown in EGTA-treated multifiber preparations of aorta from SHR and WKY rats. In desaturation curves performed on strips preloaded with ${ }^{45} \mathrm{Ca}$, a slow compartment was able to increase the ${ }^{45} \mathrm{Ca}$ efflux when the washing media contained micromolar concentrations of free $\mathrm{Ca}^{2+}$. The larger amount of Ca released by aortic strips of the hypertensive strain is supported by the high Ca content of this compartment compared with that of the normotensive WKY strain and not by differences in the rate of Ca efflux. About half of the ${ }^{45} \mathrm{Ca}$ efflux induced by $1 \mu \mathrm{M}$ free $\mathrm{Ca}^{2+}$ during the first 6 minutcs of stimulation could be blocked by ryanodine or ruthenium red, thus identifying the sarcoplasmic reticulum as a source of the ${ }^{45} \mathrm{Ca}$ release. Scveral studies reported that the skinning of muscle fibers with EGTA does not alter the ability of sarcoplasmic reticulum to sequester and release calcium. ${ }^{18)}$ We cannot affirm that the EGTA treatment has exactly the same skinning effects on membranes of aortic strips from both SHR and WKY strains. Nevertheless if the SR function is studied with isotopic techniques the chemical skinning is necessary and this uncertainty will not be solved no matter what agent is used to skin the plasma membranes.

The extrapolated values of $\mathrm{Ca}$ content in the intracellular compartment were slightly higher in SHR than in WKY, a difference that became significant due to the greater unstimulated rate of ${ }^{45} \mathrm{Ca}$ efflux exhibited by the normotensive group. These results could be in agreement with those reporting that caudal arteries treated with $2 \mathrm{mM}$ EGTA for 30 minutes empty their intracellular Ca stores to a lower degree in SHR than in WKY rats as was estimated by thcir contractile response to norepinephrine stimulation after the exposure to EGTA ${ }^{1,8)}$ At 20 minutes of washing, the average $\mathrm{Ca}$ content in the intracellular compartment of aortic strips was $163 \pm 7 \mathrm{nmol} / \mathrm{g}^{-1}$ wt for WKY and $217 \pm 7$ for SHR. This Ca pool releases $\mathrm{Ca}$ upon stimulation with micromolar free $\mathrm{Ca}^{2+}$ and it is also sensitive to Ca channel blockers of sarcoplasmic reticulum. Thus, a 
calculation of its $\mathrm{Ca}$ concentration can be made on the basis of a $5 \%$ reticular volume in aortic smooth muscle cells ${ }^{19}$ ) and a $35 \%$ fraction of smooth muscle cells in the aortic wall. ${ }^{20)}$ The calculated concentrations are $9.3 \mathrm{mM}$ in WKY and 12.5 $\mathrm{mM}$ in SHR. The larger concentration in SHR could be apparent if this strain has a larger SR volume compared to WKY. The differences in Ca content could not be attributed to strain variations in smooth muscle content of the aortic wall. Morphometric studies have shown that the fraction of total aortic medial volume occupied by smooth muscle is the same in SHR and WKY rats at the age of those used in the present study. ${ }^{211}$

Several reports showed that the contractile response of vessels is greater in SHR than in WKY rats. ${ }^{\perp, 8,11)}$ In one of these, the mesenteric resistance vessels from SHRs developed more contraction upon epinephrine stimulation than those of WKY rats, but a greater concomitant efflux of $\mathrm{Ca}$ could not be demonstrated in the hypertensive strain. ${ }^{1)}$ The authors suggested that the extrusion of $\mathrm{Ca}$ through the ATP-driven pump could be depressed in SHRs $s^{6)}$ thus masking the efflux of $\mathrm{Ca}$ from intracellular stores. Our results show that a greater intracellular pool of $\mathrm{Ca}$ can release more $\mathrm{Ca}$ upon stimulation with submicromolar and micromolar concentrations of free $\mathrm{Ca}^{2+}$ in SHRs. Thus a stimulated contractile response might be expected on this basis in vessels of genetically hypertensive rats. Results on $\mathrm{Ca}$ activity measured with fura-2 have suggested an enhanced and prolonged SR calcium release in smooth muscle cells of SHRs. ${ }^{22)}$

Differences between the amount of Ca released with $0.03 \mu \mathrm{M}$ free $\mathrm{Ca}^{2+}$ (no significant changes in rate coefficient) and the maximal release obtained with higher free $\mathrm{Ca}^{2+}$ concentrations permit calculation of the increases in $\mathrm{Ca}^{2+}$ in the extrareticular space. The values were $2.5 \mathrm{nmol} . \mathrm{g}^{-1}$ wt. $\mathrm{min}^{-1}$ in WKY and 4.2 in SHR. These values might be overestimated if part of the ${ }^{45} \mathrm{Ca}$ efflux is ${ }^{40} \mathrm{Ca}-{ }^{45} \mathrm{Ca}$ exchange. We cannot conclude from our present results if the partial blockage of $\mathrm{Ca}^{2+}$-induced ${ }^{45} \mathrm{Ca}$ efflux is due to insufficient concentrations of the channel blockers for fully deactivating the SR-Ca channel or to ${ }^{40} \mathrm{Ca}-{ }^{45} \mathrm{Ca}$ exchange.

As shown in Table III the release of Ca is higher in SHR than in WKY when the stimulation affected a compartment with greater $\mathrm{Ca}$ content and the rate of $\mathrm{Ca}$ efflux was similar in both strains (Figure 3). In spite of the fact that we did not measure the contractile response of our preparations, the present results suggest that contractions elicited by agonists inducing SR Ca release in SHRs will depend primarily on the amount of $\mathrm{Ca}$ stored in SR. Results supporting that vascular reactivity is higher in SHR than in WKY were based upon experimental protocols that included pretreatment of vessels with $2 \mathrm{mM}$ of EGTA for 20-30 minutes, ${ }^{1,8,11)}$ and those describing the opposite used 0.1 mM EGTA $^{10)}$ or did not treat the vessels with EGTA ${ }^{8,9)}$ One of these studies ${ }^{8)}$ showed that after the EGTA treatment, contractions induced by norepinephrine increased with the 
time of reexposure to Ca-containing solutions and were always higher in SHR than in WKY caudal arteries. Possibly the treatment with $2 \mathrm{mM}$ of EGTA allow an increased influx of $\mathrm{Ca}^{2+}$ through the sarcolemma during the exposure to $\mathrm{Ca}$ and more $\mathrm{Ca}$ was stored in SR of vascular smooth muscle cells from SHRs.

In summary, the $\mathrm{Ca}^{2+}$-induced $\mathrm{Ca}^{2+}$ release mechanism works at micromolar concentrations of free $\mathrm{Ca}^{2+}$ in EGTA-treated aortic strips of SHR and WKY rats with the hypertensive strain having a potentially greater content of $\mathrm{Ca}$ in the SR of its aortic smooth muscle cells.

\section{REFERENCES}

1. Cauvin $\mathrm{C}$, Johns A, Yamamoto MK, Hwang $\mathrm{O}$, Gelband $\mathrm{C}$, van Breemen $\mathrm{C}$ : $\mathrm{Ca}^{2+}$ movements in vascular smooth muscle and their alterations in hypertension. in Membrane Abnormalities in Hypertension, ed by Kwan CY, CRC Press, Booa Raton, Florida, p 145, 1989

2. Bhalla RC, Aqel MB, Sharma RV: Alpha - $_{1}$ adrenoceptor-mediated responses in the vascular smooth muscle of spontaneously hypertensive rats. Hypertension 4: S65,1986

3. Rinaldi GJ, Amado Cattaneo E, Mattiazzi A, Cingolani HE: Dissociation between calcium influx blockage and smooth muscle relaxation by nifedipine in spontaneously hypertensive rats. Circ Res 60 : 367,1987

4. Sada T, Koike $H$, Ikeda $M$, Sato $K$, Ozaki $H$, Karaki $H$ : Cytosolic free calcium of aorta in hypertensive rats. Hypertension 16: 245,1990

5. Kwan CY: Abnormalities of vascular muscle membranes in hypertension with special reference to calcium handling. in Membrane Abnormalities in Hypertension. ed by Kwan CY, CRC Press, Booa Raton, Florida, p 115, 1989

6. Kwan CY, Belbeck L, Daniel EE: Abnormal biochemistry of vascular smooth muscle plasma membrane isolated from hypertensive rats. Mol Pharmacol 17: 137, 1980

7. Bhalla RC, Webb RC, Singh D, Ashley T, Brock T: Calcium fluxes, calcium binding, and adenosine cyclic 3',5'-monophosphate-dependent protein kinase activity in the aorta of spontaneously hypertensive and Kyoto Wistar normotensive rats. Mol Pharmacol 14: 468, 1978

8. Rinaldi GJ: Norepinephrine-sensitive calcium pools in tail arteries of spontaneously hypertensive and normotensive rats. Acta Physiol Pharmacol Ther Latinoam 40: 339, 1990

9. Shibata S, Kurahashi K, Kuchii M: A possible etiology of contractile impairment of vascular smooth muscle from spontaneously hypertensive rats. J Pharnacol Exp Ther 185: 406, 1973

10. Dohi Y, Aoki K, Fujimoto S, Kojima M, Matsuda T: Alterations in sarcoplasmic dependent contraction of tail arteries in response to caffeine and noradrenaline in spontaneously hypertensive rats. $\mathrm{J}$ Hypertension 8: 262, 1990

11. Aqel MB, Sharma RV, Bhalla $\mathrm{RC}$ : Increased $\mathrm{Ca}^{2+}$ sensitivity of alfa-adrenoceptor-stimulated contraction in SHR caudal artery. Am J Physiol 250: C275, 1986

12. McClellan GB, Winegrad S: The regulation of calcium sensitivity of the contractile septum in mammalian cardiac muscle. J Gen Physiol 72: 737, 1978

13. Fabiato A: Computer programs for calculating total from specified free or free from specified total ionic concentration in aqueous solutions containing multiple metals and ligands. Methods in Enzymology. Biomembranes 157: 378, 1988

14. Feher J, LeBolt WR, Manson NH: Differential effect of global ischemia on the ryanodine-sensitive and ryanodine-insensitive calcium uptake of cardiac sarcoplasmic reticulum. Circ Res 65: 1400, 1989

15. Humerickhouse RA, Besch HR, Gerzon K, Ruest L, Sutko JL, EmmickJT: Differential activating and deactivating effects of natural ryanodine congeners on the calcium release channel of sarcoplasmic reticulum: Evidence for separation of effects at functionally distinct sites. Mol Pharmacol 44: 412, 1993

16. Stout MA, Diecke FPJ: ${ }^{45} \mathrm{Ca}$ distribution and transport in skinned vascular smooth muscle. J Pharmacol Exp Ther 225: 102, 1983 
17. Stout MA: Calcium transport by sarcoplasmic reticulum of vascular smooth muscle: I. MgATP-dependent and MgATP-independent calcium uptake. J Cell Physiol 149: 383, 1991

18. Best PM: Cardiac muscle function; results from skinned fiber preparations. Am J Physiol 244: H167, 1983

19. Ashida T, Schaeffer J, Goldman WF, Wade JB, Blaustein MP: Role of sarcoplasmic reticulum in arterial contraction: comparison of ryanodine's effect in a conduit and muscular artery. Circ Res 62 : 854,1988

20. Owens GK: Differential effects of antihypertensive drug therapy on vascular smooth muscle cell hypertrophy, hyperploidy, and hyperplasia in the spontaneously hypertensive rat. Circ Res 56: 525, 1985

21. Owens GK, Schwartz SM: Alterations in vascular smooth muscle mass in the spontaneously hypertensive rat; role of cellular hypertrophy, hyperploidy, and hyperplasia. Circ Res 51: 280, 1982

22. Eme $\mathbf{P}$, Hermsmeyer $\mathrm{K}$ : Intracellular vascular muscle $\mathrm{Ca}^{2+}$ modulation in genetic hypertension. $\mathrm{Hy}-$ pertension 14: 145, 1989 